\section{Case Reports in Dermatology}

DOI: $10.1159 / 000475543$

Published online: June 14, 2017
(C) 2017 The Author(s)

Published by S. Karger AG, Basel www.karger.com/cde

\title{
Trichoscopic Findings of Erosive Pustular Dermatosis of the Scalp Associated with Gefitinib
}

\author{
Tomohisa Fukui $^{a, b}$ Hideo Kitamura $^{b}$ Ken Harada ${ }^{b}$ Hajime Nakano \\ Daisuke Sawamura ${ }^{a}$ \\ a Department of Dermatology, Hirosaki University Graduate School of Medicine, \\ Hirosaki, Japan; ${ }^{b}$ Department of Dermatology, Aomori Central Hospital, Aomori, Japan
}

\section{Keywords}

Scarring alopecia - Gefitinib · Epidermal growth factor receptor · Trichoscopy · Erosive pustular dermatosis of the scalp

\begin{abstract}
Alopecia associated with epidermal growth factor receptor (EGFR) inhibitor therapy is a rare cutaneous side effect with the potential to progress to scarring alopecia. Thus, dermatologists should make an early diagnosis. We present the case of a 57-year-old Japanese female with scarring alopecia associated with gefitinib, which is an EGFR inhibitor, including trichoscopic findings. The patient treated with gefitinib for non-small cell lung cancer experienced skin rash and hair loss of the scalp. The scalp lesions appeared similar to erosive pustular dermatosis of the scalp. Trichoscopic examination showed follicular keratotic plugging, milky red areas, white patches, hair shaft disorder, tapering hair, and absence of follicular opening. Histological examination showed ruptured hair follicles with a perifollicular infiltration of plasma cells, lymphocytes, and histiocytes. Oral minocycline and topical steroid treatment produced no improvement. With a reduction in the gefitinib dosage, alopecia gradually improved, although scarring remained. We consider these trichoscopic findings and suspect that follicular keratotic plugging might be a finding associated with scarring alopecia due to EGFR inhibitor therapy.




\section{Introduction}

Epidermal growth factor receptor (EGFR) inhibitor, which is the standard treatment for non-small cell lung cancer, inhibits the proliferation of cancer cells and thereby not only affects cancer cells but also causes various skin toxicities. These are suspected to inhibit normal growth and differentiation of epidermal cells and hair follicles [1]. Alopecia associated with EGFR inhibitor therapy is a rare cutaneous side effect, with the potential to progress to scarring alopecia [2]. Here, we present the case of a 57-year-old Japanese female with scarring alopecia with a similar appearance to erosive pustular dermatosis of the scalp (EPDS), associated with gefitinib, including trichoscopic findings.

\section{Case Presentation}

A 57-year-old female with a 1-year history of non-small cell lung cancer began treatment with gefitinib, an EGFR inhibitor, at an initial dose of $250 \mathrm{mg}$ daily. The patient noticed erosive and papulopustular eruption on her scalp, accompanied by hair loss 2 months after initiating gefitinib. Over the next 11 months, alopecia drastically expanded over the scalp, and she was referred to our department for dermatological consultation.

Physical examination revealed painful erythema, erosion, and papulopustular crusts with alopecia over the scalp with the exception of the occipital area. The hair-pull test was positive (Fig. 1). Trichoscopy showed follicular crusts and keratotic plugging, milky red areas, white patches, hair shaft disorder, tapering hair, and absence of follicular opening with skin atrophy (Fig. 2). These findings were considered consistent with EPDS. Bacterial and mycological cultures from affected areas showed no growth. Histological examination of biopsy taken from the parietal scalp lesions showed ruptured hair follicles with a perifollicular infiltration of plasma cells and lymphocytes (Fig. 3). Perifollicular histiocytes and multinucleated giant cells were present.

Oral minocycline was initiated at a dose of $100 \mathrm{mg}$ daily, and a high-potential topical steroid was administered for 2 months. However, these did not induce any improvement in the lesions, and her alopecia progressed rapidly. On the strong demand of the patient, gefitinib was decreased to $250 \mathrm{mg}$ on alternate days. Though the eruption gradually improved, hair regrowth occurred only partially, and scars remained on the scalp 6 months after the reduction of the gefitinib dose (Fig. 4). Based on the above-mentioned findings, we made the final diagnosis of EPDS associated with gefitinib.

\section{Discussion}

EGFRs are mainly expressed in basal keratinocytes, sweat glands, and the follicular epithelium, as well as in cancer cells. EGFR inhibitors cause a range of adverse cutaneous reactions. The possible mechanisms of these cutaneous reactions may be related to the roles of EGFRs in cell differentiation, development, angiogenesis, and apoptosis [3]. On the other hand, EGFR inhibitors are thought to increase free-radical synthesis; thus, these promote the inflammatory cascade and cause follicle destructions and alopecia [4]. However, the mechanism of scalp inflammation associated with EGFR inhibitors is not fully understood. Most cases of alopecia associated with EGFR inhibitors show EPDS as our patient [5], while a few show tufted hair folliculitis (THF) [6, 7]. Because these side effects have potential to progress 
to scarring alopecia, dermatologists should make an early diagnosis. The available treatment for EPDS is topical high-potency steroids [8], though it has poor effect on EPDS associated with EGFR inhibitors [5]. The best treatment for EPDS eruption associated with EGFR is dose reduction or discontinuation of EGFR inhibitors.

In regard to the trichoscopic findings in this case, follicular keratotic plugging and absence of follicular openings are common in scarring alopecia [8]. Milky red areas and white patches are thought to reflect inflammation and scarring of the scalp. Tapering hair and hair shaft disorder are related to hair cycle changes and disorder of hair differentiation associated with EGFR inhibitors. The trichoscopic findings of most cases of EPDS reveal atrophic skin, lack of follicular ostia, and follicular crusts [9]. Thus, we diagnosed our case as EPDS eruption associated with gefitinib, resulting in scarring alopecia.

A few reports have described the trichoscopic features of scarring alopecia associated with EGFR or ERFR-like receptor inhibitors. Ena et al. [6] reported THF, which can cause scarring alopecia, in a female with breast cancer treated with lapatinib, which targets EGFR and human epidermal receptor (HER), an EGFR-like receptor. Rosman and Anadkat [7] also reported THF associated with trastuzumab, which targets human epidermal receptor. In both cases, dermoscopy revealed follicular keratosis. Although this clinical entity is different from EPDS, follicular keratotic plugging could be an expected finding in scarring alopecia associated with EGFR inhibitors.

In conclusion, it is important that the early identification and management of alopecia associated with EGFR in order to prevent expansion of scarring alopecia. The trichoscopic findings of follicular keratotic plugging could be an expected finding in scarring alopecia associated with EGFR inhibitors.

\section{Statement of Ethics}

The patient's consent to publish this case was obtained.

\section{Disclosure Statement}

The authors declare no conflicts of interest.

\section{References}

-1 Lynch TJ Jr, Kim ES, Eaby B, Garey J, West DP, Lacouture ME: Epidermal growth factor receptor inhibitor-associated cutaneous toxicities: an evolving paradigm in clinical management. Oncologist 2007;12:610-621.

2 Graves JE, Jones BF, Lind AC, Heffernan MP: Nonscarring inflammatory alopecia associated with the epidermal growth factor receptor inhibitor gefitinib. J Am Acad Dermatol 2006;55:349-353.

-3 Nanney LB, Magid M, Stoscheck CM, King LE Jr: Comparison of epidermal growth factor binding and receptor distribution in normal human epidermis and epidermal appendages. J Invest Dermatol 1984;83:385.

-4 Lacouture ME, Anadkat MJ, Bensadoun RJ, Bryce J, Chan A, Epstein JB, Eaby-Sandy B, Murphy BA; MASCC Skin Toxicity Study Group: Clinical practice guidelines for the prevention and treatment of EGFR inhibitor-associated dermatologic toxicities. Support Care Cancer 2011;19:1079-1095.

5 Toda N, Fujimoto N, Kato T, Fujii N, Nakanishi G, Nagao T, Tanaka T: Erosive pustular dermatosis of the scalp-like eruption due to gefitinib: case report and review of the literature of alopecia associated with EGFR inhibitors. Dermatology 2012;225:18-21. 


\title{
Case Reports in Dermatology
}

\begin{tabular}{l|l}
\hline Case Rep Dermatol 2017;9:44-49 \\
\hline DOI: 10.1159/000475543 & $\begin{array}{l}\text { (c) 2017 The Author(s). Published by S. Karger AG, Basel } \\
\text { www.karger.com/cde }\end{array}$ \\
\hline
\end{tabular}

Fukui et al.: Trichoscopic Findings of Erosive Pustular Dermatosis of the Scalp Associated with Gefitinib

\begin{abstract}
-6 Ena P, Fadda GM, Ena L, Farris A, Santeufemia DA: Tufted hair folliculitis in a woman treated with lapatinib for breast cancer. Clin Exp Dermatol 2008;33:790-791.

7 Rosman IS, Anadkat MJ: Tufted hair folliculitis in a woman treated with trastuzumab. Target Oncol 2010;5:295-296.

-8 Abedini R, Kamyab Hesari K, Daneshpazhooh M, Ansari MS, Tohidinik HR, Ansari M: Validity of trichoscopy in the diagnosis of primary cicatricial alopecias. Int J Dermatol 2016;55:1106-1114.

$\checkmark 9$ Starace M, Loi C, Bruni F, Alessandrini A, Misciali C, Patrizi A, Piraccini BM: Erosive pustular dermatosis of the scalp: CLINICAL, trichoscopic, and histopathologic features of 20 cases. J Am Acad Dermatol 2017. pii: S0190-9622(16)31240-3.
\end{abstract}

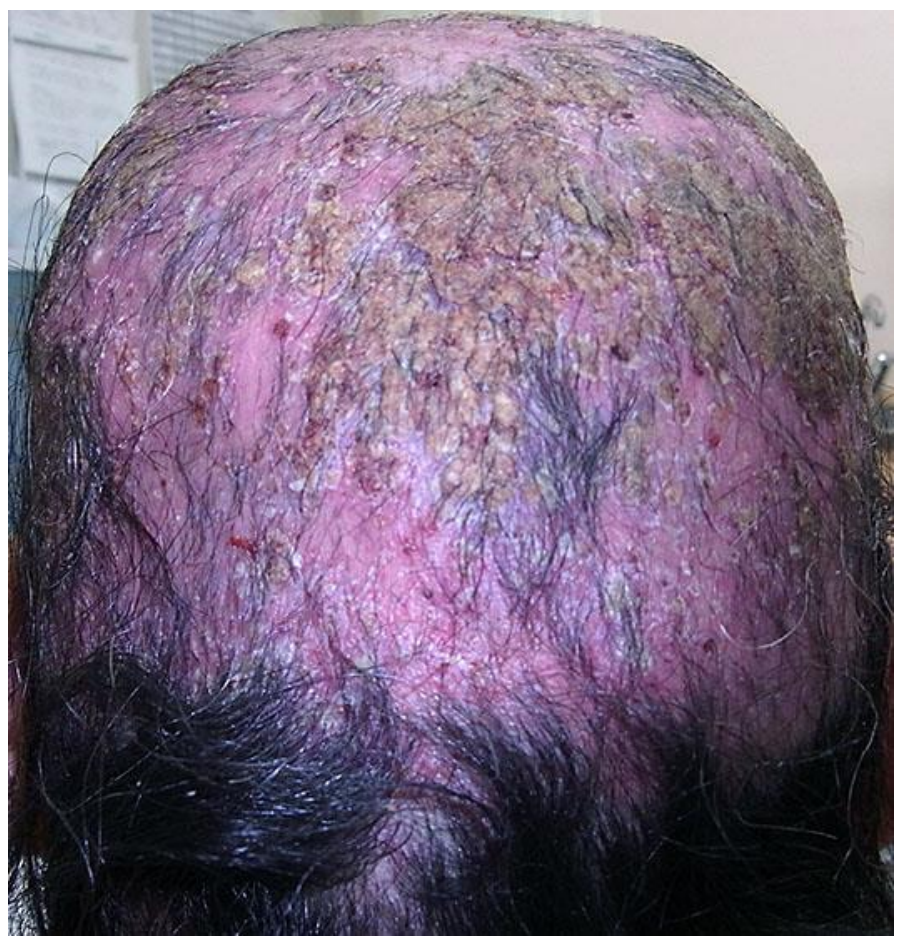

Fig. 1. Appearance of the scalp lesion after 11 months of gefitinib treatment. Erythema, erosion, and papulopustular crusts were seen over the scalp with the exception of the occipital area. The lesions appeared similar to pustular dermatosis of the scalp. 


\section{Case Reports in Dermatology}
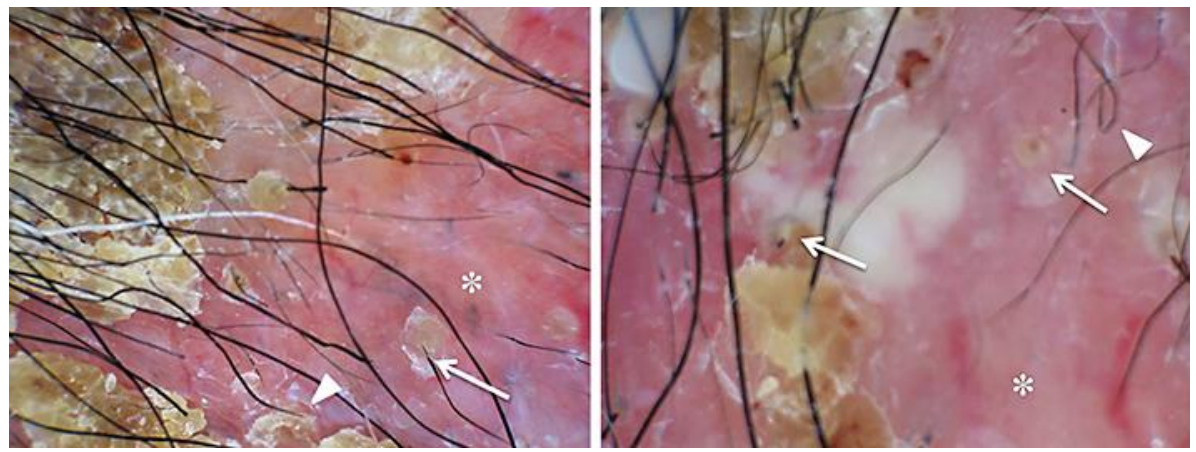

Fig. 2. Trichoscopy findings. Follicular crusts and keratotic plugging (arrow), milky red areas, white patches, hair shaft disorder, tapering hair (arrowhead), and absence of follicular opening (asterisk) with atrophic skin are seen.

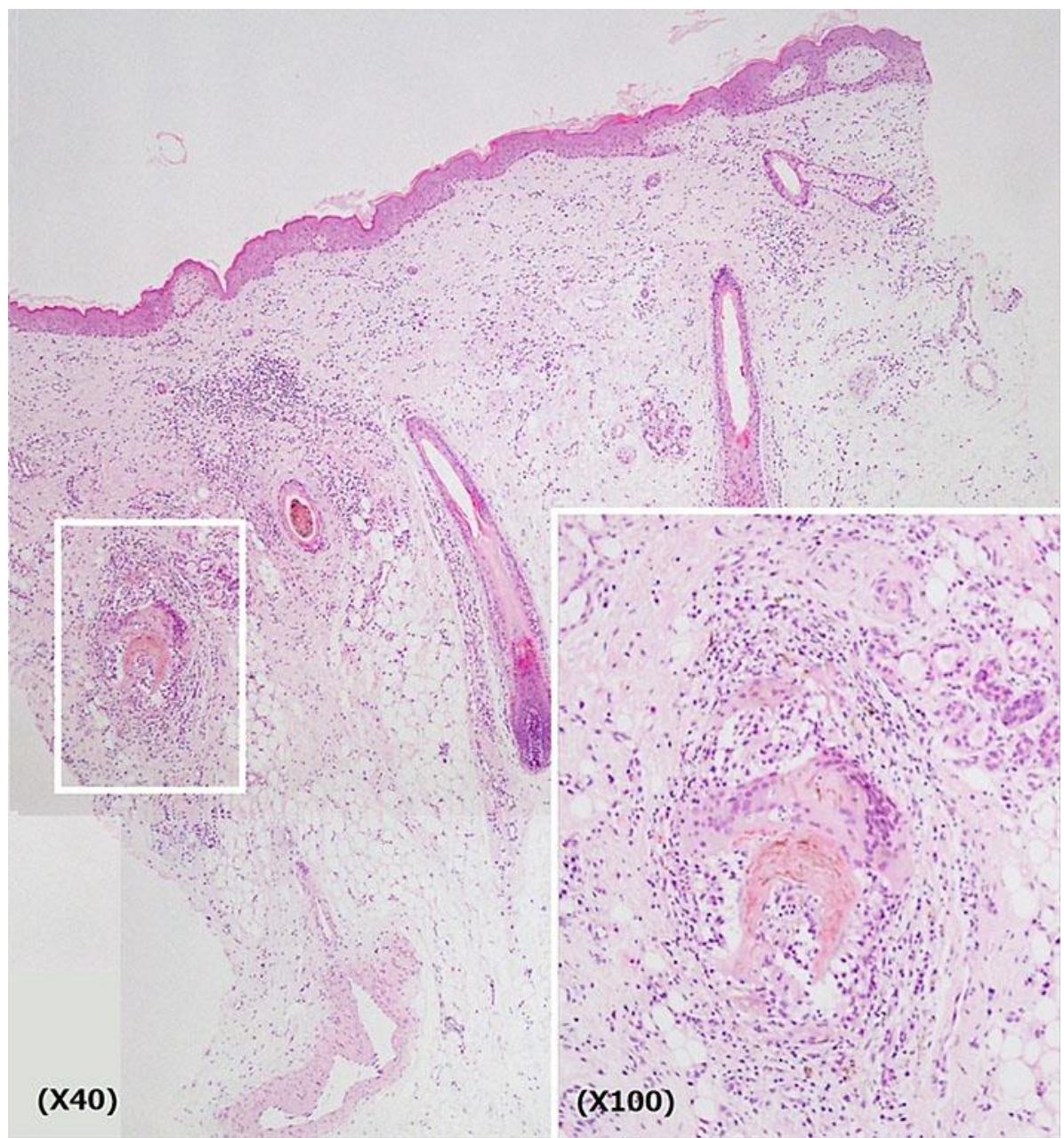

Fig. 3. Histological findings. Ruptured hair follicles with a perifollicular infiltration of plasma cells and lymphocytes are seen (hematoxylin eosin stain). 


\section{Case Reports in Dermatology}

Case Rep Dermatol 2017;9:44-49 DOI: $10.1159 / 000475543$

(C) 2017 The Author(s). Published by S. Karger AG, Basel

Fukui et al.: Trichoscopic Findings of Erosive Pustular Dermatosis of the Scalp Associated with Gefitinib

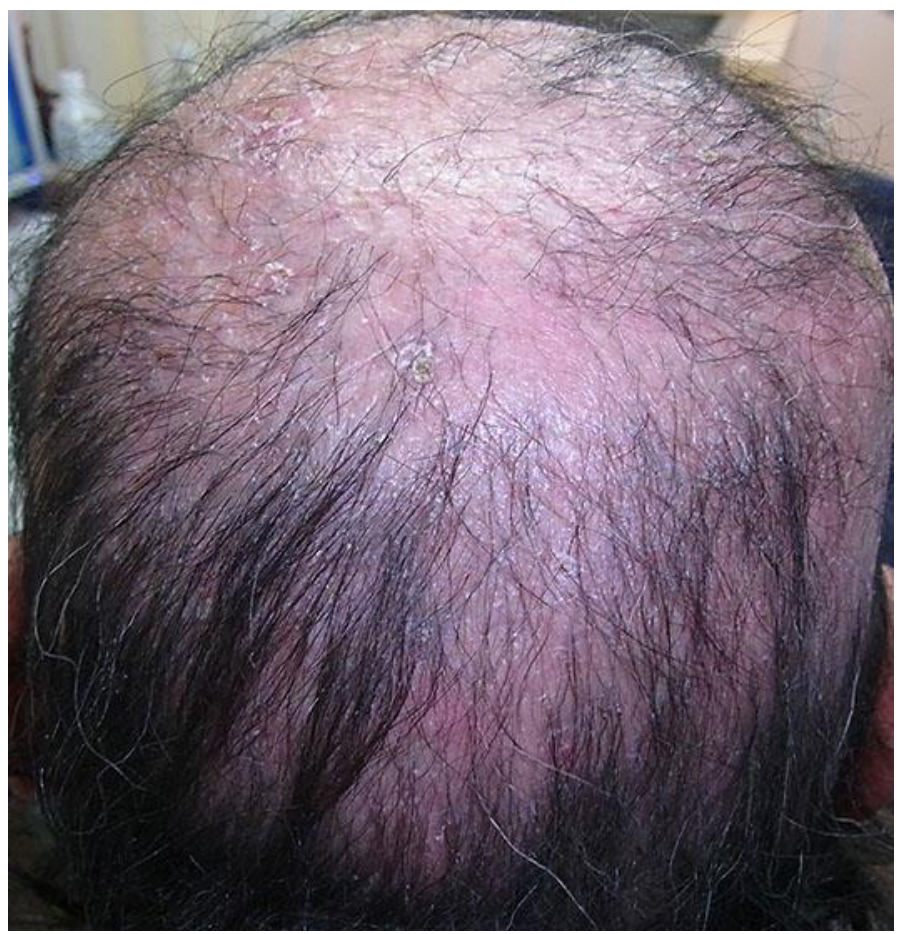

Fig. 4. Appearance of the scalp lesion 6 months after gefitinib reduction. Hair growth was observed, but scars remained. 